International Journal of Engineering Sciences \& Research Technology

(A Peer Reviewed Online Journal)

Impact Factor: 5.164

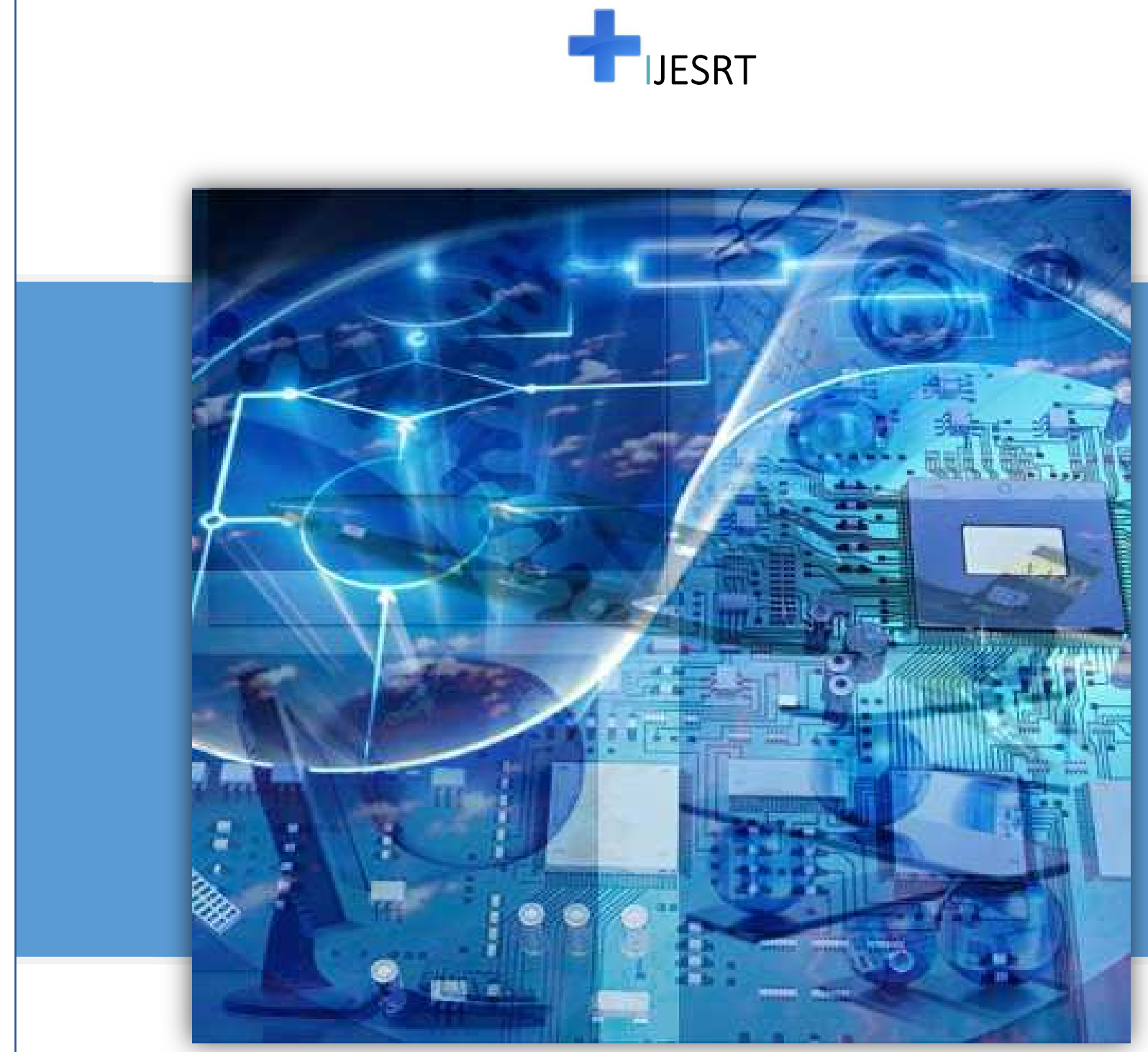

\section{Chief Editor}

Dr. J.B. Helonde
Executive Editor

Mr. Somil Mayur Shah 
INTERNATIONAL JOURNAL OF ENGINEERING SCIENCES \& RESEARCH TECHNOLOGY

\title{
DENSITY BASED TRAFFIC CONTROLLER SYSTEM USING WIRELESS SENSOR
} NETWORKS

Mr.Munaf $S^{1}$, Gohul Saravanan A ${ }^{* 2}$, Abishek $A^{2}$,Easwara Vishnu $S \mathbf{R}^{2}$

*Electronics and Communication Engineering,Sri Ramakrishna Institute of Technology,Coimbatore,India

DOI: https://doi.org/10.29121/ijesrt.v10.i3.2021.16

\begin{abstract}
This traffic controller system aims at designing a dynamic automated traffic control system where the signal and time limit will be automatically changed when it detects traffic congestion in any lane. Traffic congestion is a major problem in many cities around the world so it is urgent need to switch over from manual mode or timer mode to an automated traffic control system that has the power to make decisions on its own. The current traffic signal system is working on fixed time which may not work if one route gets more traffic than other lane. To overcome this problem, a smart traffic control system is proposed. When using this system high traffic congestion on a particular lane receives green for a longer period of time compared to the other lanes which has normal vehicle flow. Therefore, the proposed method of providing green and red light time is based on the amount of traffic congestion at the time with the help of an IR sensor and Sound sensors connected to ATmega 2560 Microcontroller.
\end{abstract}

KEYWORDS: IR sensor, Sound sensors, ATmega 2560,LED.

\section{INTRODUCTION}

Traffic congestion is one of the major problems in all big metro city. This leads to traffic accidents sometimes which may cause major deaths and injuries. Road accidents deaths caused in many cities are due to traffic-related problems. As more and more vehicles are stepping into the already congested traffic system, there is an extreme need for advanced methods to overcome the crisis. Instead of building new roads, flyovers and elevated expressway which are expensive and takes lots of time for the completion of the project. The main goal should be on availing the existing infrastructures more efficiently by using help of advanced technologies. Earlier many technologies were proposed such as image processing, RFID, induction loops etc. The survey of these technologies let us know about some of the flaws in it. To overcome from all these flaws usage of density based traffic control system is best solution. By inserting the density sensors in the middle of the road we can able to count the number of vehicles passing through that lane.

\section{EXISTING SYSTEMS}

Density activity by exploitation open tool as software system for image process by simply displaying the assorted conversion of image within the screen and at last close the box on the vehicle within the given image, the quantity of vehicle is calculated. they can calculate the density of the vehicle by exploitation mat science lab tool by comparison the four facet of the image that is given as input. they can stimulate the results of the four given input image however this can not be employed in real time applications because it is incredibly slow and therefore the software system isn't freed from value like receptive overcome this disadvantage of mat lab open software system is employed that is incredibly simple to put in and is open supply software system and may be employed in real time application in an exceedingly fast manner. Drawback of the existing system It is unreliable and cost efficient, The space required for the cloud based detecting system is large. 


\section{Proposed system}

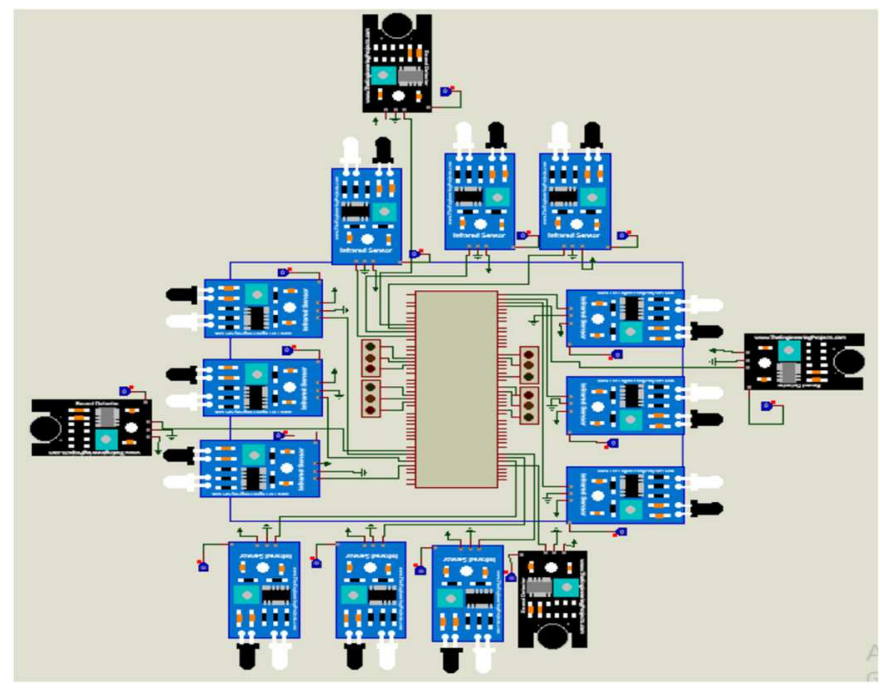

Figure 2 :Circuit diagram

The Figure shows the basic circuit connection of density based traffic controller system. The circuit consists of 12 IR sensors, 4 sound sensors, ATmega2560 microcontroller, 4 street lights. The IR transmitter looks like an LED. This IR transmitter emits IR radiation all the time. The operating voltage of this IR transmitter is said to be 2 to $3 \mathrm{v}$. These IR (infra-red) rays are invisible to human eyes. But we can view these IR rays with a camera. The IR receiver detects IR radiation transmitted by an IR transmitter. The IR receiver usually has a high resistance to mega ohms, while receiving IR radiation resistance is very low. The operating voltage of the IR receiver is also 2 to $3 \mathrm{~V}$.

\subsection{IR Sensor}

IR sensor is a main component in our system.IR sensors are placed in the side of the lane which detects the density of the vehicles present at the particular lane. The rays from the IR sensors will be transmitted into the lane .The reflected rays from the lane is captured and the output will be detected.IR sensors plays a major role in our system.

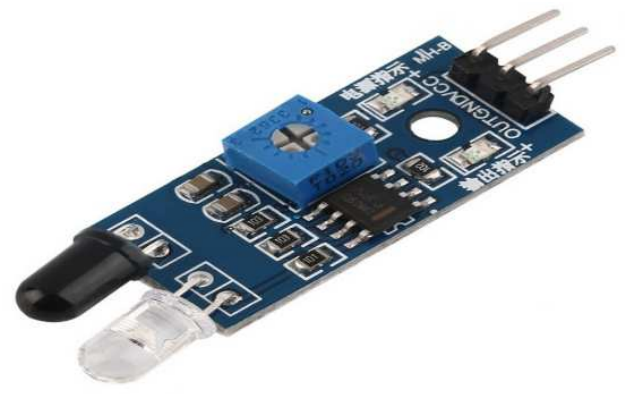

Figure 3: IR Sensor 


\subsection{Sound Sensor}

A sound sensor is an another major component in our system. Sound sensors plays a vital role by detecting the sound waves and converts the electrical signals. In our system, sound sensors are also fixed in the lane. The purpose of fixing sound sensors is to detected sound waves which is created by the vehicles like ambulances, VIP vehicles etc. The output from the sound sensors are also detected .

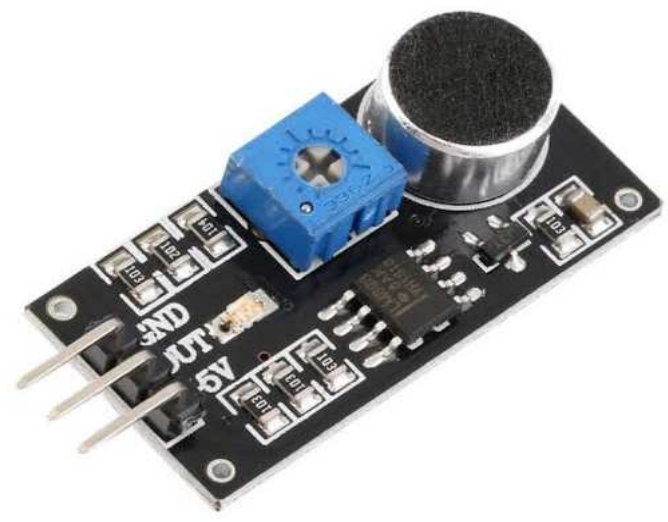

Figure 3: Sound Sensor

\subsection{LED}

A light-emitting diode (LED) is a semiconductor device.LED consumes very low energy hence it is chosen in our system. It is neither coherent nor monochromatic. It is also long lasting hence there is no need of change of LED frequently.
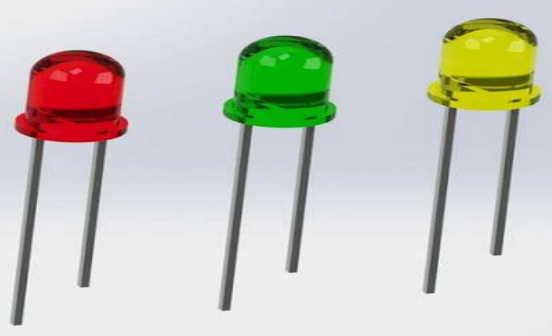

Figure 4: LED

\subsection{ATmega 2560}

The ATmega 2560 is an advanced version of ardunino which has several and output from the IR sensors and Sound sensors are also connected to the ATmega 2560 micro controller. ATmega 2560 is high performance, it consumes low power. ATmega 2560 is an eight bit microcontroller . 


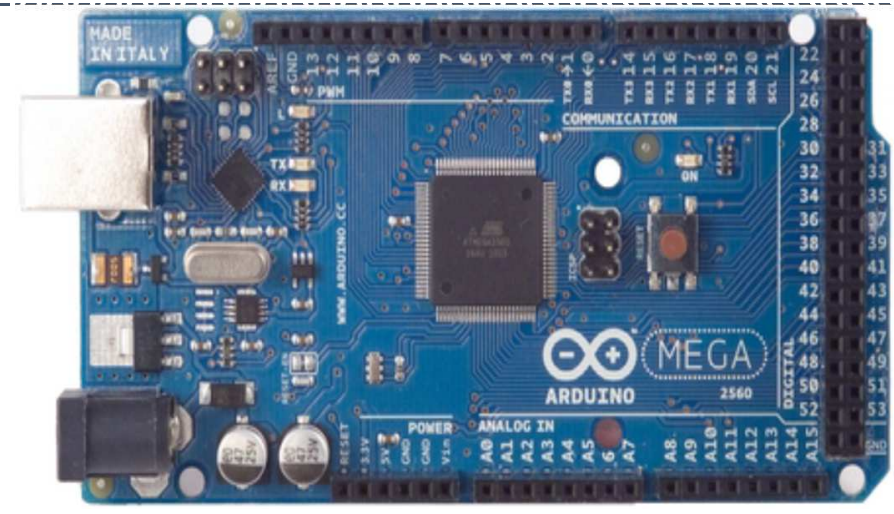

Figure 5: Atmega 2560

\section{RESULTS AND DISCUSSION}

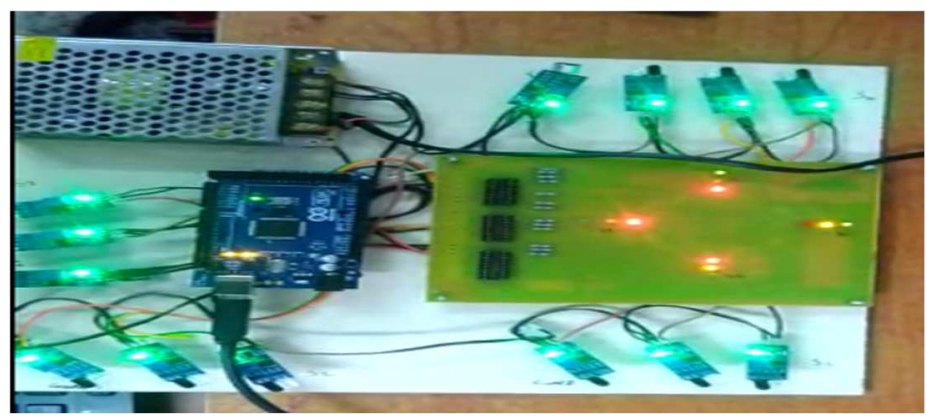

FIGURE 6: Hardware output 1

The circuit connections are to be made correctly and then we have start the kit. The IR sensor and sound sensor scans the roads R1, R2, R3, and R4. If the traffic density in road R1 is high then the signal S1 will be given green. If the traffic density in road R2 is high then the signal S2 will be given green. If the traffic density in road R3 is high then the signal S3 will be given green. If the traffic density in road R4 is high then the signal S4 will be given green. Also the traffic signals will glow in anticlockwise with delay of 10 seconds. If the sound sensor in road R1 is on then the signal S1 will be given green while others will be in red. If the sound sensor in road R2 is on then the signal S2 will be given green while others will be in red. If the sound sensor in road R3 is on then the signal $\mathrm{S} 3$ will be given green while others will be in red. If the sound sensor in road R4 is on then the signal S4 will be given green while others will be in red. The below figure represents the traffic flow signal working on different lanes. 


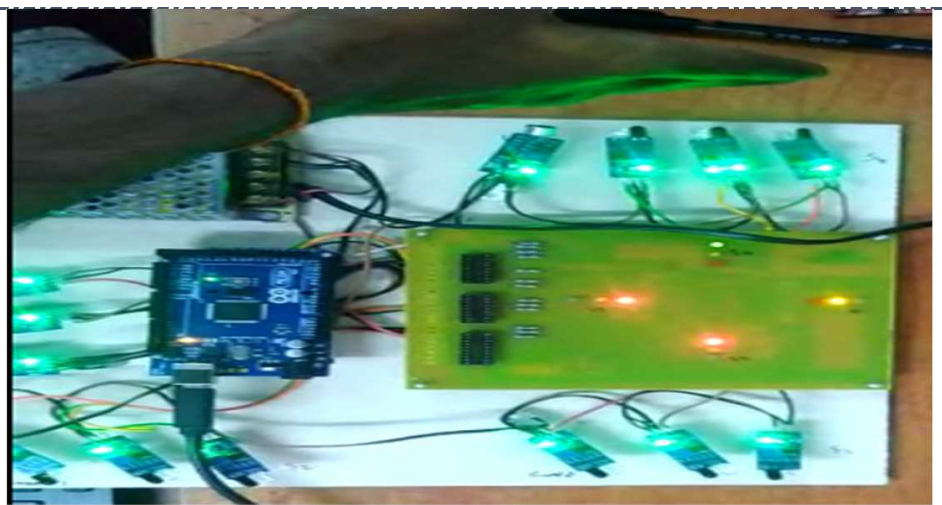

Figure 7: Hardware output 2

The proposed system of traffic control system has been successfully simulated in the Proteus 8 Professional software for Software phase. The system uses IR sensor and sound sensor for the input which has transmitter and receiver along withand a LED display for the output. The input is deeded to the microcontroller and it does the commanding part of the system it takes the decision. The simulated model of the proposed system is shown in the figures.

\section{CONCLUSION}

For this project, we designed a traffic signal system using a microcontroller. Hardware equipment is tested and the result is obtained. This project is well worth it. The implementation of this project in current day will successfully resolve traffic congestion which is a major problem in many modern cities around the world. Long term replacement of the hand signs for traffic clearance by traffic men. This leads to save us lot of valuable time especially for emergency vehicles in the event of an emergency. The work is done by the sensors which act as an artists across the road to monitor the length of the vehicles blocking the traffic. In the near future, it can be further developed using robotic vehicles, which will access the alternatives described in the Intelligent Traffic Control web application. This system cannot determine if it has two ambulances in two different modes at the same time when it reaches a neutral point. This problem can be solved by putting in place management strategies to prevent traffic control.

\section{ACKNOWLEDGEMENTS}

This research project was supported and carried out at Department of ECE, Sri Ramakrishna Institute of Technology, and Coimbatore. We would like to thank our management, principal and research supervisor for supporting us with the facility to carry out the proposed model.

\section{REFERENCES}

1. Taqi Tahmid, Eklas Hossain, "Density based smart traffic control system using Canny Edge detection algorithm for congregating traffic information”, IEEE National Conference, 2017.

2. Cuneyt Akinlar, Edward Chome, "Canny SR: Using smart routing of edge drawing to convert canny binary edge maps to edge segments", IEEE National Conference, 2015.

3. Rajeshwary Sundar, Santosh Hebbar, and Varaprasad Golla, "Implementing Intelligent Traffic control system for congestion control, ambulance clearance, and stolen vehicle detection", IEEE National conference, 2014.

4. Reda ElHakim, Abdelraman Eldesokey, Moataz Abdewahab, "TraffiSenase: A smart integrated visual sensing system for traffic monitoring”, IEEE National conference, 2015.

5. B. Janani Saradha, G. Vijiyashri, T. Subha, "Intelligent Traffic signal control system for ambulance using RFID and CLOUD”, IEEE National Conference, 2017.

http: // www.ijesrt.com@ International Journal of Engineering Sciences \& Research Technology 
6. Jiri Ruzicka, Jan Silar, Zuzana Belinova, Martin Langr, "Methods of traffic surveys in cities for comparison of traffic control systems - a case study”, IEEE International Conference, 2018.

7. Intelligent Traffic Signal Control System Using Embedded System by Dinesh Rotake and Prof.SwapniliKarmore, Innovative Systems Design And Engineering, ISSN 2222-1727 (paper) ISSN 2222-2871 (online), Vol. 3, No. 5, 2012.

8. S.Munaf, A.Bharathi, A.N.Jayanthi “An Enhanced Low Power Dual Data Injection Technique for Coarse - Grained Reconfigurable Architecture", International Journal of Innovative Technology and Exploring Engineering (IJITEE) ISSN: 2278-3075, Volume-9 Issue-2, December 2019.

9. Road Traffic Congestion Monitoring and Measurement using Active RFID and GSM Technology by Koushik Mandal, Arindam Sen, Abhijnan Chakraborty and Siuli Roy, IEEE Annual Conference on Intelligent Transportation Systems, 2011.

10. Image Processing Based Intelligent Traffic Controller by VikramadityaDangi,AmolParab, KshitijPawar and S.S Rathod. Undergraduate Academic Research Journal (UARJ), ISSN: 2278 - 1129, Vol-1, Iss-1, 2012.

11. International Journal of Innovative Research in Science, Engineering andTechnology Volume 3, Issue 3, March 2014 Density Based Traffic Signal System byK.Vidhya, A.BazilaBanu

12. S.Munaf, Sathish K "Intelligent Transport Monitoring System for School Children", International Journal for Research Trends and Innovation, Vo4 issue 1, January 2019, ISSN: 2456 - 3315 .IF 4.87.

13. DolgorsurenBatjargal, ganbatTsend, "Development of a computer model to calculatestatistics about traffic jam”, IEEE National Conference, 2017.

14. S. Munaf, S. Monika, G. Monika, V. Gopika \& S. Arthi "Auto Honking Control System For Vehicles" international journal of Engineering Sciences \& Research Technology, Vo9 issue 6, June 2020, ISSN: 2277-9655.IF 5.16. doi.org/10.29121/ijesrt.v9.i6.2020.13. Indexed: Thomson Reuters, Google scholar, Research Gate.

15. Heshem a. El. Zouka, "Collaboration Technologies for secure road traffic congestioncontrol system in Egypt", IEEE National Conference, 2017.

16. Ma Yanli, GuGaofeng, Jiang Yuan, Zhu Xuesheng, "Speed Control analysis analysisof freely work zone based on ITS", IEEE National Conference, 2014.

17. Abida Sharif, Jianping Li, MudassirKalil, "Internet of Things - smart trafficmanagement system for smart cities using big data analytics", IEEE National Conference,2017. 